\title{
Comparison of UV Index and Total Ozone Column of Aura/OMI and Ground Measurement from Nepal Himalayas
}

\author{
Rishi R. Sharma ${ }^{1 *}$, Berit Kjeldstad ${ }^{1}$, Binod K. Bhattarai ${ }^{2}$ \\ ${ }^{1}$ Department of Physics, Norwegian University of Science and Technology, Trondheim, Norway \\ ${ }^{2}$ Institute of Engineering, Pulchowk Campus, Tribhuvan University, Kathmandu, Nepal
}

\begin{abstract}
Ground UV index and total ozone measured from four stations of Nepal Himalaya using NILU UV Multiband Filter Radiometer (MBFR) were compared with that of the Aura/OMI satellite products using the data from October 2008 to December 2010. The main goal of the validation was to find how the satellite products deviate with that of ground measurement in the mountainous sites where the stations have unique set of geographical and environmental conditions. The altitudes of the stations vary from $72 \mathrm{~m}$ to $2850 \mathrm{~m}$ in a short span of horizontal distance. The comparison was done for clear-sky and cloudy-sky condition using Cloud Transmission Factor (CLT) as a proxy. It was found that UV indices estimated by the satellite have higher values compared to ground instrument. The relative difference (bias) of the four stations are varied from $34.5 \pm 24.0 \%$ to $47.9 \pm$ $17.4 \%$ for cloud free condition and from $106.4 \pm 81.44 \%$ to $286.4 \pm 254.8 \%$ for cloudy condition. The correlation coefficients are more than 0.8 for cloud free condition. The total ozone column comparison showed the mean relative difference (bias) range from $-2.17 \pm 3.52 \%$ to $2.97 \pm 3.92 \%$ under cloud free condition and $-4.42 \pm 5.64 \%$ to $1.36 \pm 6.14 \%$ under cloudy condition. The possible factors for this discrepancy are discussed and some important factors are highlighted.
\end{abstract}

Keywords: UV Index, Ozone column, NILU UV, Nepal Himalaya, OMI data

\section{Introduction}

Increased UV radiation over the Earth surface caused by stratospheric ozone layer depletion due to excessive use of greenhouse gases like CFC drew much concern in mid 1980s (Farman et al., 1985). Although limited exposure of UV radiation is beneficial for human health because of its role in vitamin D formation, over exposure of it causes detrimental effects on human health, terrestrial and aquatic ecosystems, biogeochemical cycles, and materials (UNEP, 2010). The level of UV radiation on the earth surface is generally described by the UV index (WHO, 2002). The UV index is derived from the convolution of surface UV irradiance with the erythemal action spectrum (Mckinlay and Diffey, 1987), and ranges from zero, when no sun is present, to more than 15 at midday in certain tropical regions. A UV index more than three requires some type of sun protection be used (WHO, 2002).

Measurements taken from different instruments, either from ground instrument or space satellite, are used to estimate the surface UV index. Ground instruments vary in terms of spectral resolution, cost, data quality, and sophistication to handle the instrument. One of the instruments compromising between the high quality spectroradiometer and broadband radiometer is the Moderate Band Filter Radiometer (MBFR). These instruments measure incoming UV radiation in selected bandwidths which are capable of generating the UV spectrum and other UV products such as Total Ozone Column (TOC), Cloud Transmission Factor, and UV dose rates (UV Index) using a suitable radiative transfer model (Britt et al., 2003). Satellites also estimate the surface 
UV radiation by measuring UV radiance and reflectivity, and some data from other sources. TOMS (Total Ozone Mapping Spectrometer) and its heritage OMI (Ozone Monitoring Instrument) are the key satellites in measuring UV radiation. Various factors like solar zenith angle, ozone level, cloud, surface albedo, and geometry of the location may play a role to affect the UV radiation on the ground besides the instrumental and modelling uncertainties (Arola et al., 2002). Some of the factors, particularly solar elevation, stratospheric ozone and altitude's influence on UV radiation are understood with reasonably well so that their effects could be handled through the radiative transfer model. On the other hand, influence on UV radiation due to cloud, surface albedo and aerosol is still not fully understood because of its dynamics and complexity.

For cloud free, snow free and aerosol free atmosphere, UV radiation reaching the earth surface can be estimated from satellites with reasonable accuracy using total ozone and surface reflectivity (Krotkov et al., 2001). Having same cloud reflectivity with differing amount of absorbing aerosol present in the cloud itself also affects the surface UV radiation. Cloud is therefore a dominant atmospheric variable affecting the UV radiation reaching the earth surface. In OMI UV product, cloud is estimated from the Lambert Equivalent Reflectivity (LER) derived from the OMI measured radiance (I360) near $360 \mathrm{~nm}$ (Krotkov, 2002, Eck et al., 1995). The ground instrument (NILU UV) utilised Cloud Transmission Factor (CLT), the ratio of measured to clear sky surface irradiance with no aerosol and zero surface albedo, to estimate the surface UV radiation (Britt et al., 2003).

Satellite's UV products such as UV irradiance, UV doses, total ozone, aerosol, and UV index from TOMS/Nimbus 7 satellite and Aura/OMI satellite, are compared or validated extensively with ground instruments mostly from mid latitude and few cases of high latitude sites including Europe, North America, South America, Australia and Antarctica. Kalliskota et al. (2000) compared Nimbus-7/TOMS daily UV doses of three stations Ushuaia (Argentina), Palmer (Antarctica), and San Diego (California) with that of ground based spectroradiometer data from 1991 to 1993 . They found that satellite's estimated value of daily UV doses was $25 \%$ higher than ground measured value for no snow cover station (San Diego), and $-13 \%$ and $-35 \%$ lower for snow-covered stations Ushuaia and Palmer respectively. Buchard et al. (2008) have compared Total Ozone Column (TOC) and UV irradiance data from Aura-OMI satellite with that of ground measured data using spectroradiometer from two French sites of northern France. They compared the two TOC values obtained from OMI-TOMS algorithm and OMI-DOAS algorithm and found that the relative difference is in good agreement better than 5\% and 7\% for OMI-TOMS and OMI-DOAS algorithm respectively in both the stations under all sky conditions. Similarly, spectral UV on clear sky condition is also better than $10 \%$ except at solar zenith angle larger than $65^{\circ}$ and erythemal dose rates and erythemal daily doses were $15 \%$ higher than ground values under clear sky and snow free ground surface.

Fioletov et al. (2004) have compared the monthly mean UV index obtained from TOMS data and ground data of 28 stations over United States and Canada from 1980 to 1990. They found that for the stations with snow in the ground, the noontime monthly average UV index values were lower as much as $60 \%$ as compared to ground data. However, in the summer the TOMS UV index was 10 to $30 \%$ higher than ground measured values using Brewer spectroradiometer. Tanskanen et al. (2007) also compared the daily erythemal doses of 17 stations covering different latitude and longitude, mostly from mid latitude and high latitude sites. They found that those sites with 
modest loading of aerosol under clear sky and snow free condition, the overestimation by satellite was within 0 to $10 \%$ whereas the sites with significant aerosol loading, the overestimation was $50 \%$ for snow free surfaces and underestimation of $50 \%$ for snowy surfaces.

The UV radiation level at low latitude and high altitude region like Nepal Himalayas is believed to be high because of relatively low level of stratospheric ozone in the tropical region, more and direct solar irradiance throughout the year because of the vicinity of the equator, and less atmospheric attenuation because of its elevation from the sea level. Four UV monitoring stations equipped with Moderate Band Filter Radiometer (MBFR) are established at different altitudes of Nepal Himalaya in recent years (2008-2009). These data are particularly important to validate the similar data obtained from the satellite which has relatively longer acquisition period. To know the spatial and temporal variation of UV radiation in the region ground and satellite measurement may complement to each other.

The main objective of the paper is to compare the OMI overpass data (UV index and total ozone column) with that of the ground instruments from the Nepal Himalayas. Different sections divide the paper. After the introductory section, the section 2 describes the Ground based and satellite based data. Section 3 provides some important results of the comparison for different sky conditions. Section 4 discusses the finding and section 5 concludes the paper.

\section{Data and Methods}

\subsection{Description of Ground Station and Instrumentation}

Solar Radiation and Aerosol in Himalayan Region (SAHR) project under the Institute of Engineering of Pulchowk Campus of Tribhuvan University has been operating and maintaining four UV monitoring stations in Nepal since 2008/2009 (Table 1). The project is funded by Norwegian Program for Development, Research and Education (NUFU) with close collaboration from Norwegian University of Science and Technology (NTNU).

The stations cover elevation range of $70 \mathrm{~m}$ to $2850 \mathrm{~m}$ in the southern Himalayas within the latitude range of $26.45^{\circ}$ to $27.72^{\circ}$ and longitude range of $83.32^{\circ}$ to $87.27^{\circ}$. Nepal gets about $80 \%$ rain during the monsoon season (June to September) from south-east monsoon originating from the Bay of Bengal. Pollutants are usually at low level in this period and sky often covered by clouds. During the winter (December to February), rain mainly occurs due to westerly disturbance, and its effect gradually slow down from west to east. These four stations have also unique local setting. The lowermost station, Biratnagar, lies in the southern flat land. It is a moderate size urban city close to Indian boarder. Temperature is mild and hot during the year and may reach above $40^{\circ} \mathrm{C}$. Pokhara station is situated in a valley of Middle Mountain with altitude of $850 \mathrm{~m}$ above mean sea level. Pollutants usually settled down by afternoon rain. Total rainfall in a year exceeds $4000 \mathrm{~mm}$. Kathmandu station lies in the capital valley of middle mountain range of elevation $1350 \mathrm{~m}$ with more than 3 million populations. Bowl shaped valley and formation of inversion layer often trap the pollution at the bottom of the valley. The lower atmosphere of the valley is often hazy throughout the winter unless a rain settled the pollution. Lukla station lies in the southern slope of High Mountain nearby Mountain Everest at an elevation of $2850 \mathrm{~m}$. The atmosphere is relatively clean as compared to other stations. 
Table 1: Nepal UV monitoring stations and their short descriptions

\begin{tabular}{|c|c|c|c|l|}
\hline $\begin{array}{c}\text { Station } \\
\text { (Instrument ID) }\end{array}$ & $\begin{array}{c}\text { Latitude } \\
(\mathbf{N})\end{array}$ & $\begin{array}{c}\text { Longitude } \\
(\mathbf{E})\end{array}$ & $\begin{array}{c}\text { Altitude } \\
(\mathbf{m})\end{array}$ & \multicolumn{1}{|c|}{ Site Description } \\
\hline $\begin{array}{c}\text { Biratnagar } \\
(\mathbf{1 3 3})\end{array}$ & $26.45^{\circ}$ & $87.27^{\circ}$ & 72 & $\begin{array}{l}\text { Plain low land area with urban } \\
\text { environment, data acquisition date } \\
02.02 .2009\end{array}$ \\
\hline $\begin{array}{c}\text { Pokhara } \\
(\mathbf{1 3 7})\end{array}$ & $28.22^{\circ}$ & $83.32^{\circ}$ & 850 & $\begin{array}{l}\text { A valley with urban environment, } \\
\text { rain occurs frequently at } \\
\text { afternoon, data acquisition date } \\
01.12 .2008\end{array}$ \\
\hline $\begin{array}{c}\text { Kathmandu } \\
(\mathbf{1 3 6})\end{array}$ & $27.72^{\circ}$ & $85.32^{\circ}$ & 1350 & $\begin{array}{l}\text { Bowl shaped valley and capital } \\
\text { city, dust and aerosol common in } \\
\text { winter, data acquisition date } \\
04.10 .2008\end{array}$ \\
\hline $\begin{array}{c}\text { Lukla } \\
(\mathbf{1 3 5})\end{array}$ & $27.69^{\circ}$ & $86.73^{\circ}$ & 2850 & $\begin{array}{l}\text { Mountainous rural area, snow } \\
\text { cover at the mountain tops during } \\
\text { winter, Data acquisition date } \\
\text { 05.10.2009 }\end{array}$ \\
\hline
\end{tabular}

All four stations are equipped with multi-band filter radiometer (MBFR) manufactured by Norwegian Institute for Air Research (NILU). The NILU-UV instrument has five channels in UV region with centre wavelength at $302,312,320,340$ and $380 \mathrm{~nm}$ and bandwidths of approximately $10 \mathrm{~nm}$ at full width half maximum (FWHM) (Britt et al., 2003). It has also a sixth channel which measures photosynthetic active radiation (PAR) in the wavelength range 400-700 $\mathrm{nm}$. Data taken from multi band filter radiometer (MBFR) combined with radiative transfer model provide reliable data on biologically effective UV dose rates (UV Index), total ozone column, effective cloud optical depth or cloud transmission, and high wavelength resolution UV spectrum (Britt et al., 2003). Dahlback (1996) has given all the details to estimate these parameters and found good agreement with the high-resolution spectroradiometer. The NILU-UV instrument is temperature stabilized at $50^{\circ} \mathrm{C}$. Four NILU-UV instruments are installed at the four stations whereas a fifth instrument is kept as a reference instrument for mobile calibration. To track the sensitivity of the instrument, relative calibration is performed every month and the absolute calibration of the reference instrument traceable to the WMO standard spectroradiometer was performed in 2010.

\subsection{Aura-OMI UV index}

Aura is a multinational satellite of collective effort from USA, the Netherlands and Finland and flown in July 2004. Aura has four instruments one of them is Ozone Monitoring Instrument (OMI). OMI provides information of various atmospheric variables such as ozone, aerosols, clouds, surface UV irradiance, and other trace gases (Kazadzis et al., 2009). OMI is a wide 
swath, sun synchronous, nadir viewing, near-UV and visible spectrometer that measures solar UV and visible radiation in the range of 270 to $500 \mathrm{~nm}$ (Tanskanen et al., 2007). It covers swath of $2600 \mathrm{~km}$ with spatial resolution of $13 \times 24 \mathrm{~km}$ at nadir. The orbital period of Aura satellite is about 98 minute and equatorial crossing time is 13:42 hour local time. It scans the earth surface during ascending mode. One of the advantages of the satellite data is the global coverage and all weather capability.

OMI first estimates the ground UV irradiance assuming clear sky condition and later a cloud modification factor is used to estimate the ground UV under cloudy condition. If the ground surface is also covered by snow, a surface albedo is also used in the model. Cloud modification factors are derived from the reflectivity measurement. Absorbing aerosol is not accounted in the present version of OMI UV data products which might cause the systematic bias in the OMI data. The details can be found in the OMI ATBD documents (Levelt et al., 2002)

\subsection{Methods}

UV indices and Ozone column obtained from OMI overpass database and four UV monitoring sites from Nepal Himalayas are compared. The comparison was instantaneous with that of satellite overpass time so that the influence of changing atmospheric condition is minimal. Since very low value of UV index is unstable for the comparison (Tanskanen et al., 2007), a threshold value of ground UV index 0.5 (weighted action spectrum equivalent to $12.5 \mathrm{~mW} / \mathrm{m}^{2}$ ) is taken in this study.

In UV range, surface albedo is usually around 0.02 to 0.07 in most of the land surfaces (Eck et al., 1995). Dry sands has higher albedo but less than 0.1. Snow has usually very high albedo, up to $90 \%$ for fresh snow. Therefore, choosing a threshold of 0.1 is reasonably a good decision to separate the snowy surface and non-snowy surface (Tanskanen et al., 2007). Therefore, in this study climatological surface albedo, less than 0.1 is taken as snow free condition. Since, the stations studied in the paper have snow free surfaces most of the time in a year, only the snow free condition is considered. Cloudy days and cloudy free days are separated based on the Cloud Transmission Factor (CLT), which is a ratio of measured irradiance to calculated cleay-sky irradiance with zero aerosols and zero surface albedo for a particular solar zenith angle (Britt et al., 2003). Spectral channel where ozone absorption is minimal, is taken to calculate the CLT. It may be larger than $100 \%$ when instrument observed unobscured sun and at the same time receives diffuse radiation from cloud scattering. The threshold value of cloudy and non-cloudy days was chosen by observing daily oval shape pattern of UV index. In presence of cloud, the theoretical oval shape curve may have several kinks. 

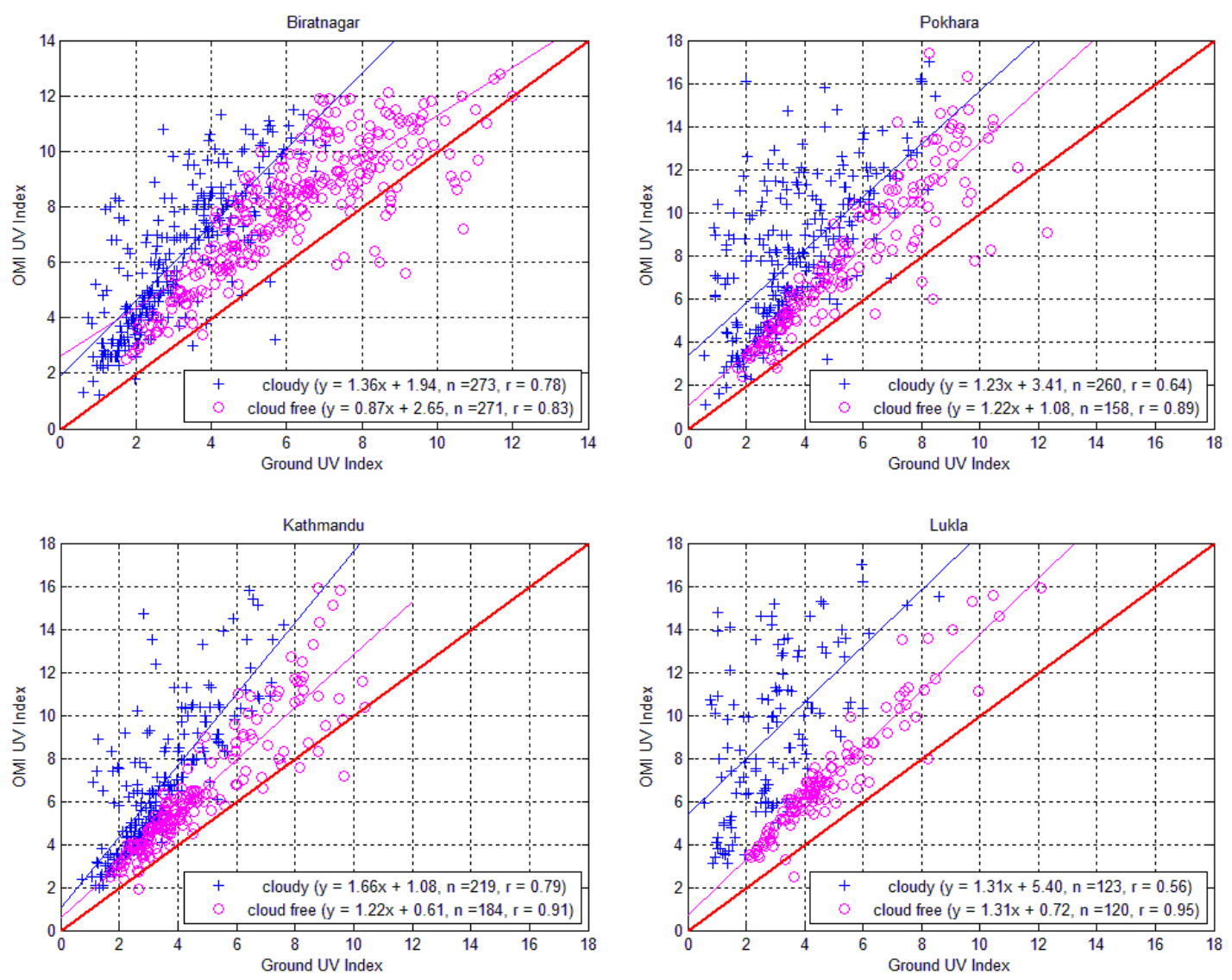

Figure 1: Scatter plots showing OMI and Ground UV indices of four stations (Biratnagar, Pokhara, Kathmandu, and Lukla) under cloud free and cloudy condition. Regression equation, number of matching pairs and correlation coefficients are also shown in respective figures.

Scatter plots of satellite and ground UV index and total column ozone are used to illustrate the differences. Slope, intercept, mean relative difference (bias) and correlation coefficient as well as monthly average bias and its standard deviation were used to compare the UV indices and ozone.

\section{Data Comparison}

\subsection{Coincident $U$ V Index}

The scatter plots between the ground measured and satellite (OMI) estimated coincident UV indices of all four stations under cloud free (and snow free) and cloudy condition are shown in Figure 1 where $\mathrm{x}$-axis represents ground measured and $\mathrm{y}$-axis represents the satellite estimated UV index. Red solid line is the bisectrix of 1:1 ratio, solid magenta line is a linear regression line for cloud free condition, and blue line is for the regression line for cloudy condition. The regression equation, number of coincident cases and correlation coefficient are also depicted in the Figure. The selection criteria of cloud free and snow free is described in the section 2.3 and Table 2 provides the statistics for the comparison. 
The number of matching pairs (coincident overpass data) under cloudy free condition varies from 120 (Lukla, $2850 \mathrm{~m}$ ) to 271 (Biratnagar, $72 \mathrm{~m}$ ). The plots of the coincident pairs show that satellite overestimates the ground measured UV index. The mean relative differences as defined by (OMI-GD)/GD*100, varies from $34.5 \pm 24.0 \%$ (Biratnagar) to $47.9 \pm 17.4 \%$ (Lukla) for cloud free cases. The mean values of ground measured UV index vary from 4.6 to 6.2 whereas satellite estimated values vary from 6.3 to 8.0. The correlation coefficient exceeds 0.83 .

Table 2: Descriptive statistics for UV index comparison for cloud free and cloudy condition.

\begin{tabular}{|l|c|c|c|c|c|c|c|c|}
\hline \multicolumn{1}{|c|}{ Stations } & $\begin{array}{c}\text { Cases } \\
(\mathbf{n})\end{array}$ & $\begin{array}{c}\text { Mean } \\
\text { GD } \\
\text { UVI }\end{array}$ & $\begin{array}{c}\text { Mean } \\
\text { OMI } \\
\text { UVI }\end{array}$ & Slope & Intercept & $\begin{array}{c}\text { Mean } \\
\text { Rel. } \\
\text { Diff } \\
(\%)\end{array}$ & $\begin{array}{c}\text { Std. of } \\
\text { Mean } \\
\text { Rel. } \\
\text { Diff } \\
(\%)\end{array}$ & $\begin{array}{c}\text { Cor. } \\
\text { Coeff. }\end{array}$ \\
\hline \multicolumn{7}{|c|}{ Cloud Free Cases } \\
\hline Biratnagar & 271 & 6.2 & 8 & 0.87 & 2.65 & 34.5 & 24.0 & 0.83 \\
\hline Pokhara & 158 & 5.6 & 7.9 & 1.22 & 1.08 & 44.8 & 23.1 & 0.89 \\
\hline Kathmandu & 184 & 4.6 & 6.3 & 1.22 & 0.61 & 37.7 & 20.7 & 0.91 \\
\hline Lukla & 120 & 4.8 & 7 & 1.31 & 0.72 & 47.9 & 17.4 & 0.95 \\
\hline & & & \multicolumn{7}{|c|}{ Cloudy Cases } & & & \\
\hline Biratnagar & 273 & 3.1 & 6.2 & 1.36 & 1.94 & 113.8 & 83.2 & 0.78 \\
\hline Pokhara & 260 & 3.6 & 7.9 & 1.23 & 3.41 & 147.8 & 148.5 & 0.64 \\
\hline Kathmandu & 219 & 3.4 & 6.7 & 1.66 & 1.08 & 106.4 & 87.4 & 0.79 \\
\hline Lukla & 123 & 2.9 & 9.2 & 1.31 & 5.4 & 286.4 & 254.8 & 0.56 \\
\hline
\end{tabular}

Under cloudy condition (CLT less than threshold value), the scatter plots of ground and satellite UV indices is also depicted in Figure 1. The number of coincident pairs varied from 123 (Lukla) to 273 (Biratnagar). The mean values of ground UV indices vary from 2.9 to 3.6 whereas OMI estimated mean values vary from 6.2 to 9.2 . The correlation coefficients vary from 0.56 to 0.79 (Table 2) and the relative differences vary from $106.4 \pm 81.44 \%$ (Biratnagar) to $286.4 \pm 254.8 \%$ (Lukla) under the cloudy condition.

Monthly mean values of relative differences (bias) of ground and OMI and the data variation within \pm 1 standard deviation is plotted in Figure 2 for both the cloud free and cloudy condition. For Biratnagar, the monthly mean biases varied from $6.5 \pm 13.6 \%$ (July) to $71 \pm 11.5 \%$ (April) under cloud free condition and $81 \pm 51.8 \%$ (July) to $155 \pm 116.1 \%$ (April) under cloudy condition. In general, the differences have minimum values during the monsoon season (JuneSeptember), and maximum values during the pre-monsoon (March-May) season. 

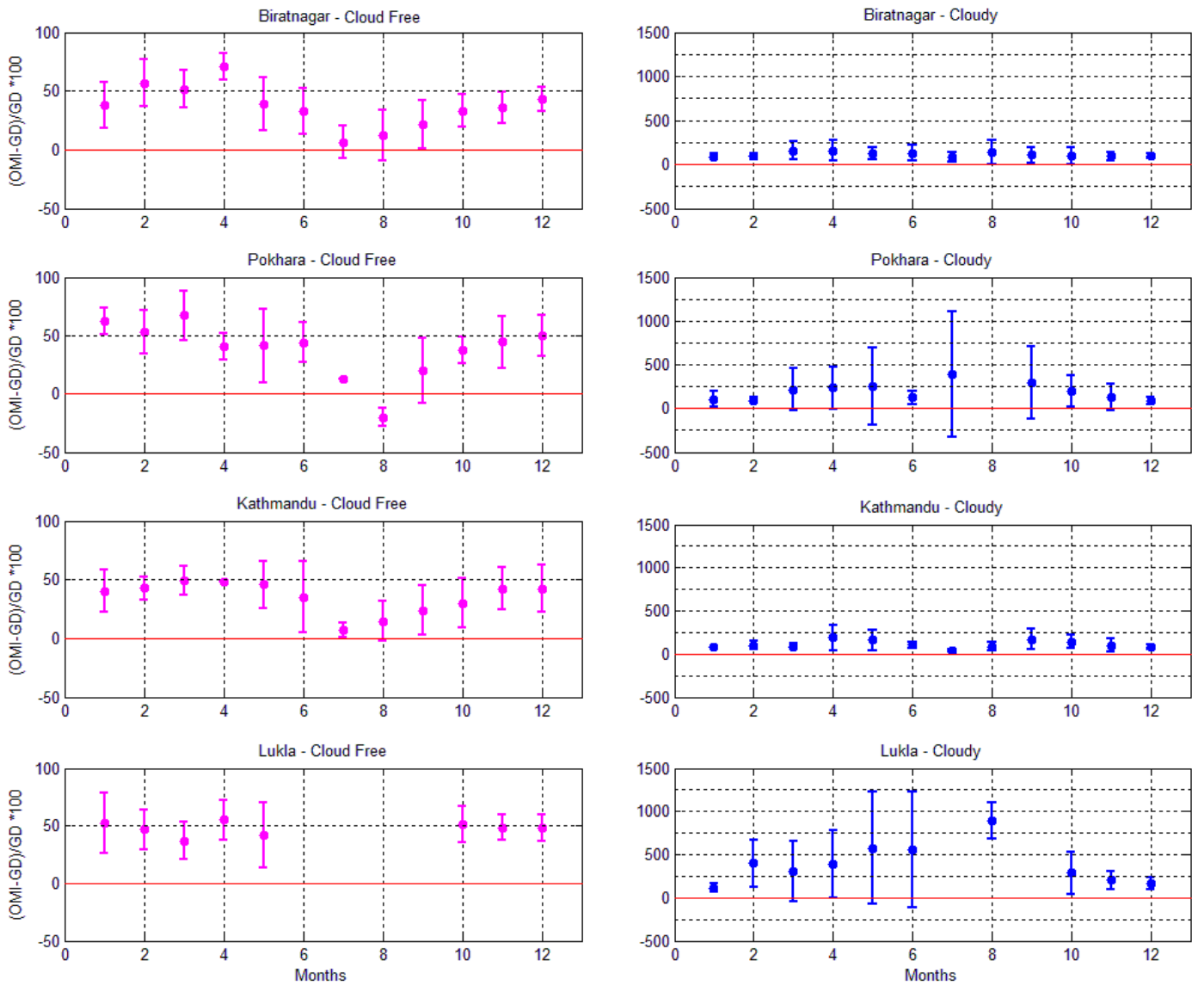

Figure 2: The monthly mean values of relative differences (bias) for OMI and Ground UV Index (dots in the figure) for four stations under cloud free condition (left) and cloudy conditions (right). Variation of the data (relative differences) assuming normal distribution is also shown with the line of \pm 1 sigma from the mean with the vertical bar. The plots from top to bottom are Biratnagar, Pokhara, Kathmandu, and Lukla respectively. The blank in some of the months is due to data gap.

\subsection{Coincident Ozone}

The scatter plots of Total Ozone Column (TOC) obtained from OMI overpass data and ground instruments for both the cloud free and cloudy cases are shown in Figure 3. The mean relative difference (bias) ranges from $-2.17 \pm 3.52 \%$ to $2.97 \pm 3.92 \%$ and correlation coefficients are more than 0.85 for all the stations under cloud free condition. Under cloudy condition, the differences are $-4.42 \pm 5.64 \%$ to $1.36 \pm 6.14 \%$ and correlation coefficients are slightly less than the clear sky cases. 

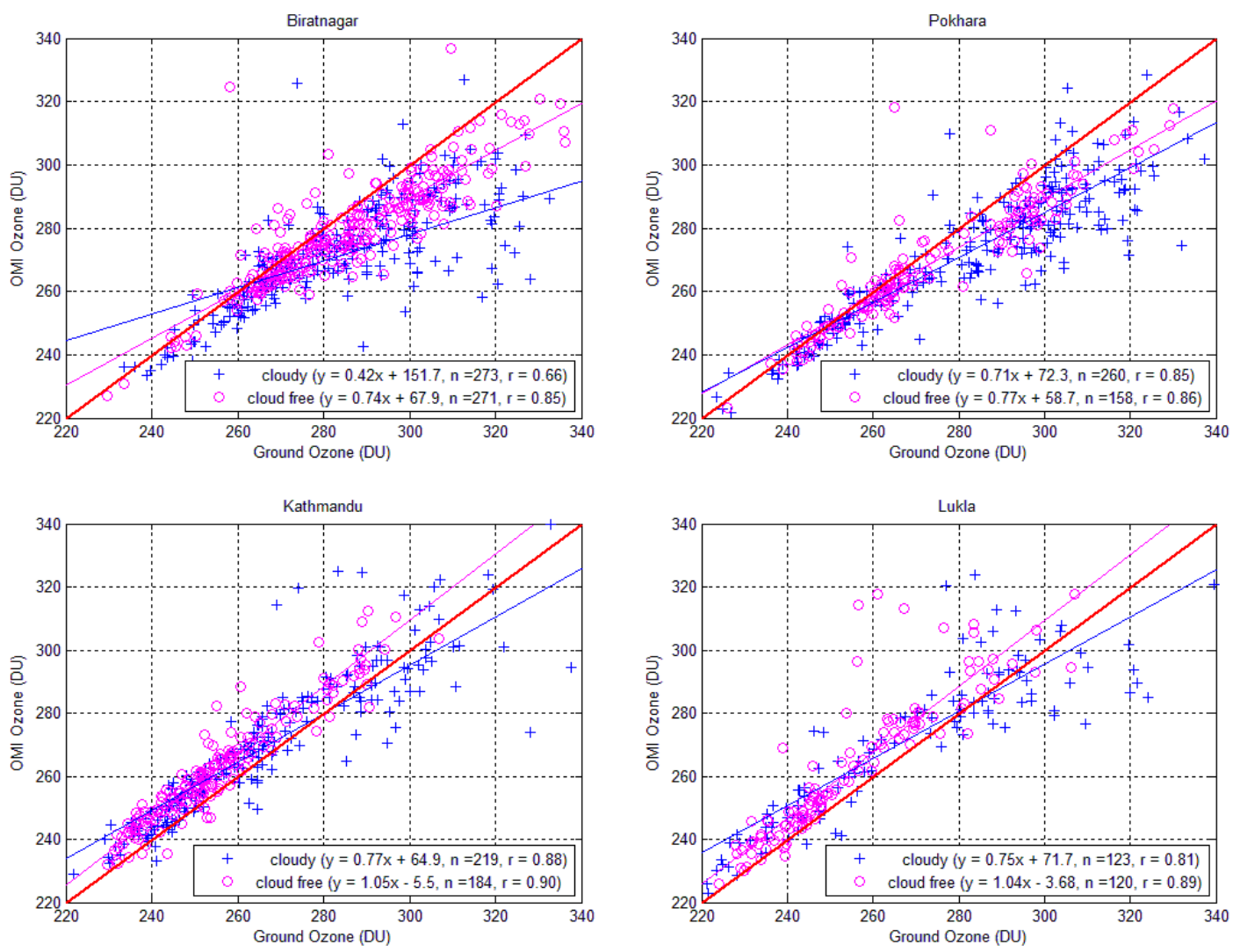

Figure 3: Scatter plots of coincident Total Ozone Column (TOC) obtained from OMI overpass data and four ground stations for cloud free (magenta) and cloudy (blue) conditions.

In absolute unit, the mean ozone column of Biratnagar (72 m) obtained from OMI was 285 DU which was about 6 DU more than the ground average. Similarly, for Luka $(2850 \mathrm{~m})$ the average ozone column obtained from OMI was 255 DU which was about 8 DU less than the ground measured value. Under cloudy condition, the average ozone value of Biratnagar was $286 \mathrm{DU}$ which was 14 DU more than the ground measured value, and for Lukla OMI average was 271 DU which was 3 DU less than ground values.

The monthly mean relative difference (bias) of the Ozone column for cloud free and cloudy cases for all stations is shown in Figure 4. Under cloudy free condition, the relative difference of Biratnagar station is varied from $-0.29 \pm 1.115 \%$ for January to $-4.37+1.14 \%$ for April. The monthly mean difference was highest for Kathmandu $(14.01+12.08 \%)$ for February. The general pattern of Ozone differences in different months is that under cloudy condition, the OMI underestimate the Ozone column as measured by the ground instrument. 


\section{Discussion}

UV index and total ozone column from Aura/OMI satellite and four ground stations are compared using the Cloud Transmission Factor as a proxy to separate the cloud from the nocloud cases. The comparison is based on the coincident data pairs. UV index is widely used indices for dissemination among the general people. Many developed countries routinely forecast the UV index for their territory. However, most of the developing countries still do not have such information. It is believed that in the low latitude and high altitude areas, the UV index is often above a threshold value where some precaution is necessary to protect its harmful effect. Although tropical region is a main source of ozone formation but due to the atmospheric circulation, tropical region has usually lower level of ozone as compared to mid-latitude and high latitude. It is well known that low level of stratospheric ozone is associated with high level of surface UV radiation.

Table 3: Descriptive statistics for ozone comparison for cloud free and snow free condition

\begin{tabular}{|c|c|c|c|c|c|c|c|c|}
\hline Stations & Cases (n) & $\begin{array}{c}\text { Mean } \\
\text { OMI O3 }\end{array}$ & $\begin{array}{c}\text { Mean } \\
\text { GD O3 }\end{array}$ & Slope & Intercept & $\begin{array}{c}\text { Mean } \\
\text { Rel. } \\
\text { Diff } \\
(\%)\end{array}$ & $\begin{array}{c}\text { Std. of } \\
\text { Rel. } \\
\text { Diff } \\
(\%)\end{array}$ & $\begin{array}{l}\text { Cor. } \\
\text { Coeff. }\end{array}$ \\
\hline \multicolumn{9}{|c|}{ Cloud Free Cases } \\
\hline Biratnagar & 271 & 285.5 & 279 & 0.74 & 67.94 & -2.17 & 3.52 & 0.85 \\
\hline Pokhara & 158 & 274.3 & 269.6 & 0.77 & 58.67 & -1.55 & 4.27 & 0.86 \\
\hline Kathmandu & 184 & 255.4 & 262.8 & 1.05 & -5.52 & 2.9 & 3.09 & 0.9 \\
\hline Lukla & 120 & 255.1 & 262.7 & 1.04 & -3.68 & 2.97 & 3.92 & 0.89 \\
\hline \multicolumn{9}{|c|}{ Cloudy Cases } \\
\hline Biratnagar & 273 & 285.6 & 271.9 & 0.42 & 151.77 & -4.42 & 5.64 & 0.66 \\
\hline Pokhara & 260 & 285.6 & 274.8 & 0.71 & 72.25 & -3.55 & 4.71 & 0.85 \\
\hline Kathmandu & 219 & 268.5 & 270.9 & 0.77 & 64.92 & 1.11 & 4.08 & 0.88 \\
\hline Lukla & 123 & 271 & 273.9 & 0.75 & 71.67 & 1.36 & 6.14 & 0.81 \\
\hline
\end{tabular}

When comparing the satellite estimated UV products with that of ground instrument one has to aware the fundamental difference due to scale. Ground data is a representative of small local area whereas satellite data like OMI represents an average areal value of 13 x $24 \mathrm{~km}^{2}$. Temporal and spatial variation of the affecting factors (cloud, elevation, slope, aerosol distribution, surface 
types etc.) within a satellite's grid must be taken into account to fully assess the quality of satellite UV data. Lacking such assessment may causes the differences in data comparison.

UV index and ozone data of four stations from Nepal Himalayas established at the end of 2008 to 2009 were used for the comparison. Ground data up to the end of 2010 are taken for the comparison.
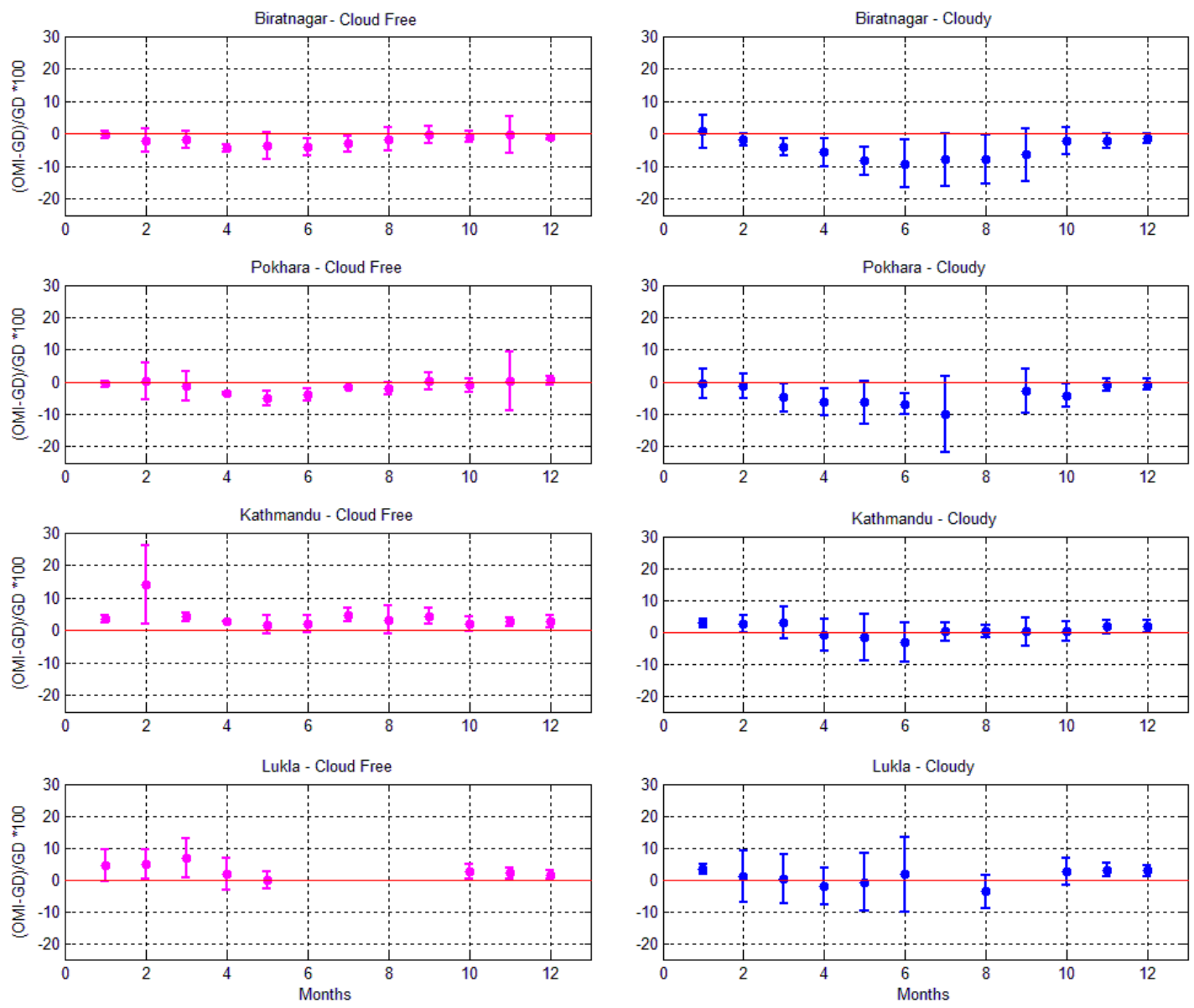

Figure 4: Monthly mean ozone bias and its standard deviation $( \pm 1 \sigma)$ is plotted as a vertical bar from the mean (filled circle) for cloud free and cloudy condition of all four stations. Left column of plots is for cloud free condition and the right column represents for cloudy condition.

Results presented in the section 3, had shown that OMI overestimates the ground measured UV index under both the conditions. In the cloud free condition, the relative differences are varied from $34.5 \pm 24.0 \%$ (Biratnagar) to $47.9 \pm 17.4 \%$ (Lukla). The mean ground UV indices is varied from 4.6 (Kathmandu) to 6.2 (Biratnagar) whereas the same from OMI is varied from 6.3 (Kathmandu) to 8.0 (Biratnagar). The correlation coefficients were more than 0.83 for all stations. The monthly biases for all stations had more or less same trend. The maximum differences are found during the pre- monsoon season (March-May) and the minimum was found during the rainy season (June to September). This difference is likely due to the aerosol 
scavenging by the rain in that season. The biases often found less than $10 \%$ in the rainy season. The constrasting result of Lukla station $(2850 \mathrm{~m})$, where the difference is the highest, cannot explan fully by aerosol effects only. This is a relatively pristine site as compared to other stations. The monthly biases also vary from $36.7 \pm 16.4 \%$ (March) to $55.3 \pm 17.2 \%$ (April), although there was no matching pairs during the rainy months (June to September). It may likely that such discrepancy in such a remote site is partly due to the altitudinal differences, snow reflection from the nearby snow capped mountains, improper surface albedo. The relative difference of other three stations (Biratnagar, Pokhara and Kathmandu) is close to the others findings.

Previous studies have also concluded that where the absorbing aerosol load is high, the UV index overestimation by OMI as compared to ground measured values could reach as much as $50 \%$ (Tanskanen et al., 2007). UV irradiance comparison from Aura/OMI satellite and ground based Brewer spectroradiometer from Rome station of Italy has shown the OMI overestimation by $30 \%$ for all sky data and $28 \%$ for cloud free data (Ialongo et al., 2008). In Thessaloniki, an urban environment in Greece, erythemally weighted overpass irradiance obtained from OMI was found $20 \%$ higher than the ground based Brewer measurement (Kazadzis et al., 2009). Similarly, OMI noontime erythemal UV dose rates (UV index) compared with broadband instrument data from four Thai stations had shown that OMI overestimation was 30 to $60 \%$ for all data and 10 to $40 \%$ for cloudless data (Buntoung and Webb, 2010). The result of the present study is very much close to the study done in Thailand. One similarity is that both are from the low latitude reason and instrument used also much similar at least they are not using the high resolution spectroradiometer.

The relative differences of total ozone column under cloud free condition vary from $-2.17 \pm$ $3.52 \%$ (Biratnagar) to $2.97 \pm 3.92 \%$ (Lukla) where Biratnagar and Pokhara stations has negative bias and Kathmandu and Lukla, has positive bias. The correlation coefficients were more than 0.85 for all the stations. The mean ozone column obtained from ground instrument varies from 255.1 to 285.5 (DU) and OMI ozone column varies from 262.7 to 279.0 (DU). The relative differences found in this study is also similar to the others findings done in other parts of the world. Study from US showed that in an average there was positive bias of $3.04 \pm 1.7 \%$ under all sky conditions (Quinton et al., 2008). Comparison of OMI ozone and ground based spectroradiometer data from two French stations also showed that the agreement was better than $5 \%$ for most of the points (Buchard et al., 2008).

Under cloudy condition, the UV index overestimation by OMI as compared to the ground values is further increased. The OMI overestimation was in the ranges from $106.4 \pm 81.44 \%$ (Kathmandu) to $286.4 \pm 254.8 \%$ (Lukla). This means resolving cloud effect is still a challenge. Similarly, the mean values of total ozone column were deviated more under cloudy condition as compared to cloud free condition. The differences vary from $-4.42 \pm 5.64 \%$ (Biratnagar) to 1.36 $\pm 6.14 \%$ (Lukla) under cloudy condition. Although, Lukla has rather small difference in mean value but the data scattered more as compared to the other stations.

The discrepancy between the Aura/OMI and NILU-UV instrument is partly attributed due to the boundary layer absorbing aerosol which was not taken into account in the present OMI/UV estimation algorithm (Tanskanen et al., 2007; Ialongo et al., 2008; Kazadzis et al., 2009; Cachorro et al., 2010). OMI UV Index comparison was found very close to the ground measurement at the pristine sites where aerosol load is very low. One study done by the authors of this paper was also found that the relative differences in Norway were below $20 \%$ for cloud 
free and snow free condition and the differences are further narrowed in those stations which is believed to be the pristine sites. Although there was no simultaneous measurement about the aerosol content in the four stations, the aerosol load in Kathmandu station could be higher than the others because of the heavily populated urban areas (more than 3 million populations), poor road condition, uncontrolled vehicular, industrial and brick kiln emission, biomass burning in nearby villages, and bowl shaped valley. Inversion layer often created in the winter and early in the morning also help to keep the high aerosol load. The monthly mean values of UV index comparison also reveal this fact. During the monsoon (June to September), the UV index estimation of OMI for Kathmandu station was better than the other months.

Cloud is the most influencing factor for OMI-Ground discrepancy. In general cloud suppress the surface UV radiation but partly cloudy sky with unobscured sun increases the UV radiation reaching the earth surface due to added effect of cloud scattering besides the direct and diffuse radiation. The proxy chosen in the study to separate the cloud free days and cloudy days is threshold value of cloud transmission factor (CLT). The threshold values often differ day by day even for clear skies and it also differ in station to station due to local atmospheric conditions. The CLT obtained from the ground instrument is valid for small area which might differ for OMI grid size. The relationship between the relative differences (bias) and cloud transmission factor obtained from ground instrument for Lukla station was found to be non-linear (Figure 5).

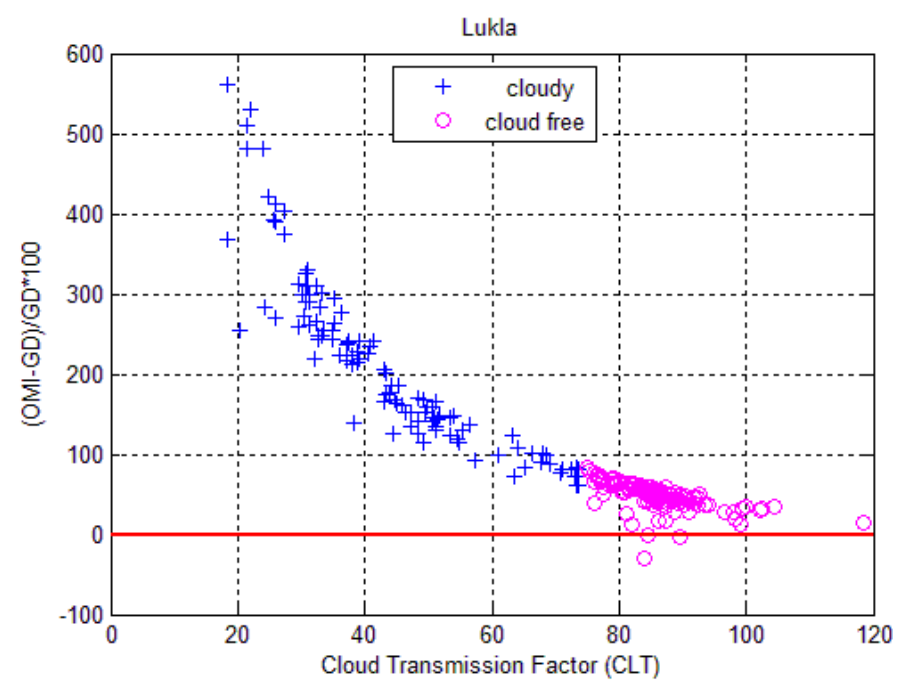

Figure 5: Plot showing dependence of relative differences (biases) on cloud transmission factor for Lukla station

The Figure 5 also shows that even for the clody free condition (circle in the figure), there is dependence of the cloud factor. One point is to note that the cloud transmission factor also includes the scattering of non-absorbing aerosols. Others stations have also similar dependence as Figure 5, but less severe. 


\section{Conclusion}

UV index and ozone data from the Aura-OMI satellite is compared with the ground data from four stations of Nepal Himalayas. The ground data were measured using NILU UV multiband filter radiometer. Altitude of the ground stations has varied from $72 \mathrm{~m}$ to $2850 \mathrm{~m}$ and the sites have covered a remote mountain site to heavily populated urban areas. The stations have covered flat land to valley and mountain. The sizes of valley were relatively smaller than OMI grid size so that OMI grid could also cover different landscape and environmental condition than the ones from the valley. The comparison was instantaneous so that the temporal variation of atmospheric condition was minimal.

The comparison is performed by considering two sky conditions: clear sky and cloudy sky. Cloud Transmission Factor was used as a proxy to separate the clear sky and cloudy sky. Time plot of UV index for each day was plotted and ideal oval shaped curves were identified assuming that cloud presence would create several kinks in the ideal oval plot. The CLT values of clear sky plots were noted and a threshold value of CLT was identified.

For the clear sky and snow free case, the OMI estimated UV index was than the ground instrument. The OMI overestimation was $34.5 \pm 24.0 \%$ to $47.9 \pm 17.4 \%$ for cloud free condition and from $106.4 \pm 81.44 \%$ to $286.4 \pm 254.8 \%$ for cloudy condition. Similarly, the total ozone column comparison showed that the mean relative difference (bias) ranges from $-2.17 \pm 3.52 \%$ to $2.97 \pm 3.92 \%$ under cloud free condition and $-4.42 \pm 5.64 \%$ to $1.36 \pm 6.14 \%$ under cloudy condition. The UV index differences were higher in the pre monsoon season and lower in the monsoon season. Scavenging the absorbing aerosol in the monsoon was mainly responsible for smaller biases. The UV index comparison between the satellite and ground has further revealed that cloud is the most dominating factor in day-to-day variation of UV index. Cloud generally suppresses the surface UV radiation whereas partly cloudy sky often enhances the surface UV radiation. The differences between the OMI and GD UV index often exceeded 100\% under the cloudy condition. The bias had strong dependence with that of Cloud Transmission Factor.

The bias in the total ozone column data of AURA/OMI satellite and ground instrument was generally better than $5 \%$ in both the sky conditions.

\section{REFERENCES}

[19] Anton M., Cachorro V. E., Vilaplana J. M., Toledano C., Krotkov N. A., Arola A., Serrano A. and la Morena B. de., Comparison of UV irradiances from Aura/Ozone Monitoring Instrument (OMI) with Brewer measurements at El Arenosillo (Spain) part 1: Analysis of parameter influence, Atmos. Chem. Phys., 10, 5979-5989, www.atmos-chem-phys.net/10/5979/2010/, doi: 10.5194/acp-10-5979-2010, 2010.

[20] Arola A., Kalliskota S., Outer P. N. den, Edvardsen K., Hansen G., Koskela T., Martin T. J., Matthijsen J., Meerkoetter R., Peeters P., Seckmeyer G., Simon P. C., Slaper H., Taalas P. and Verdebout J., Assessment of four methods to estimate surface UV radiation using satellite data by comparison with ground measurements from four 
stations in Europe, Journal of Geophysical Research, 107, No. D16, 4310, doi:10.1029/2001JD000462, 2002.

[21] Høiskar B. A. K., Haugen R., Danielsen T., Kylling A., Edvardsen K., Dahlback A., Johnson B., Blumthaler M. and Schreder J., Multichannel moderate-bandwidth filter instrument for measurement of the ozone-column amount, cloud transmittance, and ultraviolet dose rates, Applied Optics, 42, No 18, pp 3472-3479, 2003.

[22] Buchard V., Brogniez C., Auriol F., Bonnel B., lenoble J., Tanskanen A., Bojkov B. and Veefkind P., Comparison of OMI ozone and UV irradiance data with ground based measurement at two French sites, Atmos. Chem. Phys., 8, 4517-4528, 2008.

[23] Buntoung A. and Webb A. R., Comparison of erythemal UV irradiance from Ozone Monitoring Instrument (OMI) and ground-based data at four Thai stations, Journal of Geophysical Research, 115, No. D18215, doi:10.1029/2009JD013567, 2010.

[24] Cachorro V. E., Toledano C., Anton M., Berjon A., Frutos A de., Vilaplana J. M., Arola A. and Krotkov N. A., Comparison of UV irradiance from Aura/Ozone Monitoring Instrument (OMI) with Brewer measurement at El Arenosillo (Spain)- Part 2; Analysis of site aerosol influence, Atmos. Chem. Phys., 10, 16385-16423, 2010.

[25] Dahlback A., Measurements of biologically effective UV doses, total ozone abundances, and cloud effects with multichannel, moderate bandwidth filter instruments, Applied Optics, 35, 33, 1996.

[26] Eck T. F., Bhartia P. K. and Kerr J. B., Satellite estimation of spectral UVB irradiance using TOMS derived total ozone and UV reflectivity, Geophysical Research Letters, 22, 5, pp 611-614, 1995.

[27] Farman J. C., Gardiner B. G. and Shanklin J. D., Large losses of the total ozone in Antarica reveal seasonal $\mathrm{ClO}_{\mathrm{x}} / \mathrm{NO}_{\mathrm{x}}$ interaction, Nature, 315, 207-210, 1985.

[28] Fioletov V. E., Kimlin M. G., Krotkov N., McArthur L. J. B., Kerr J. B., Wardle D. I., Herman J. R., Meltzer R., Mathews T. W. and Kaurola J., UV index climatology over the United States and Canada from ground-based and satellite estimates, J. Geophys. Res., 109, D22308, doi:10.1029/2004JD004820, 2004.

[29] Ialongo I., Casale G. R. and Siani A. M., Comparison of total ozone and erythemal UV data from OMI with ground-based measurement at Rome station, Atmos. Chem. Phys., 8, 3283-3289, 2008.

[30] Kalliskota S., Kaurola J., Taalas P., Herman J. R., Celarier E. A. and Krotkov N. A., Comparison of daily UV doses estimated from Nimbus 7/TOMS measurements and ground-based spectroradiometer data, J. Geophys Res., 105, D4, 5059-5067, 2000.

[31] Kazadzis S., Bais A., Arola A., Krotkov N., Kouremeti N. and Meleti C., Ozone Monitoring Instrument spectral irradiance products: comparison with ground based measurements at an urban environment, Atmos. Chem. Phys. Discussions http://www.atmos-chem-phys-discuss.net/8/17467/2008, 2009. 
[32] Krotkov N. A., Herman J. R., Bhartia P. K., Fioletov V. and Ahmad Z., Satellite estimation of spectral surface UV radiance 2. Effects of homogeneous clouds and snow, J. Geophys Res., 106, D11, pp 11743-11759, 2001.

[33] Krotkov N. A., Herman J., Bhartia P. K., Seftor C., Arola A., Kaurola J., Taalas P., Vasilkov A., OMI Surface UV Irradiance Algorithm, Editors: P. Stammes and R. Noordhoek, ATBD-OMI-03, Version 2, August 2002.

[34] Levelt P. F., Veefkind J. P., Voors R. H. M. and Vries J. de, OMI Algorithm Theoretical Basis Document, Volume I OMI Instrument, Level 0-1b processor, Calibration \& Operations, 2002.

[35] P. F. Levelt (Editor), R. Noordhoek (Layout), ATBD-OMI-01, Version 1.1, August 2002

[36] McKinlay A. F. and Diffey B. L., A reference action spectrum for ultraviolet induced erythema on human skin, in: Human Exposure to Ultraviolet Radiation. pp. 83-87, 1987.

[37] Tanskanen A., et al., Validation of daily erythemal doses from Ozone Monitoring Instrument with ground based UV measurement data, J. Geophys. Res., 112, D24S44, doi:10.1029/2007JD008830, 2007.

[38] UNEP: Environmental effects of ozone depletion and its interactions with climate change: assessment, 2010.

[39] WHO: Global Solar UV Index, a practical guide, a joint recommendation of World Health Organization, World Meteorological Organization, United nations Environment Programme and International Commission on Non-Ionizing Radiation Protection, WHO/SDE/OEH/02.2, 2002. 